\title{
Association between Wnt inhibitory factor 1 and receptor tyrosine kinase-like orphan receptor 2 protein expression and the clinical pathological significance in benign and malignant pancreatic lesions
}

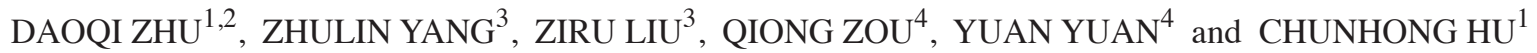 \\ ${ }^{1}$ Department of Oncology, Second Xiangya Hospital, Central South University, Changsha, Hunan 410011; \\ ${ }^{2}$ Department of Oncology, No. 163 Central Hospital of Chinese People's Liberation Army, Changsha, Hunan 410003; \\ ${ }^{3}$ Research Laboratory of Hepatobiliary Diseases, Second Xiangya Hospital, Central South University, \\ Changsha, Hunan 410011; ${ }^{4}$ Department of Pathology, Third Xiangya Hospital, \\ Central South University, Changsha, Hunan 410013, P.R. China
}

Received April 12, 2016; Accepted November 25, 2016

DOI: $10.3892 / 01.2017 .5704$

\begin{abstract}
Pancreatic cancer is one of the most malignant types of tumor. It is important to elucidate the underlying molecular mechanisms of pancreatic tumorigenesis and to identify novel biomarkers as therapeutic targets of pancreatic cancer. In the present study, the protein expression levels of Wnt inhibitory factor 1 (WIF1) and receptor tyrosine kinase-like orphan receptor 2 (ROR2) were examined in a collection of pancreatic ductal carcinoma and benign pancreatic lesion tissue samples using immunohistochemistry. The positive expression rate of WIF1 protein in pancreatic ductal carcinoma was demonstrated to be significantly decreased compared with that of the paracancerous tissue, benign lesions and wild-type pancreatic tissue $(\mathrm{P}=0.002, \mathrm{P}<0.0001, \mathrm{P}=0.001$, respectively). The positive expression rate of ROR 2 protein in pancreatic ductal carcinoma was demonstrated to be significantly increased compared with that of the paracancerous tissue, benign lesions and wild-type pancreatic tissue $(\mathrm{P}<0.0001)$. There was a negative association between WIF1 and ROR2 expression in the pancreatic ductal carcinoma samples $(\mathrm{P}=0.004)$. The survival period of patients with negative WIF1 and positive ROR2 protein expression was demonstrated to be significantly decreased compared with
\end{abstract}

Correspondence to: Professor Chunhong Hu, Department of Oncology, Second Xiangya Hospital, Central South University, 139 Renmin Middle Road, Changsha, Hunan 410011, P.R. China E-mail: huchunh@medmail.com.cn

Abbreviations: ROR2, RTK-like orphan receptor 2; RTK, receptor tyrosine kinase; sFRP, secreted Frizzled-related protein; WIF1, Wnt inhibitory factor 1

Key words: Wnt inhibitory factor 1 , receptor tyrosine kinase-like orphan receptor 2, adenocarcinoma of pancreatic duct, chronic pancreatitis, pancreatic intraepithelial neoplasia that of patients with positive WIF1 and negative ROR2 protein expression $(\mathrm{P}<0.0001)$. The expression levels of WIF1 and ROR2 protein reflected the incidence, development, clinical and biological behavior, and prognosis of pancreatic ductal carcinoma. Patients with negative WIF1 and positive ROR2 protein expression had poor prognosis. The results indicate that WIF1 and ROR 2 are important biomarkers in pancreatic cancer.

\section{Introduction}

Pancreatic cancer is one of the most fatal and malignant types of tumor (1). Most patients, when diagnosed, have developed late-stage pancreatic cancer and have lost the opportunity for radical surgery (2). Therefore, it is crucial to elucidate the underlying molecular mechanisms of pancreatic tumorigenesis and to identify novel biomarkers as therapeutic targets of pancreatic cancer.

Wnt proteins belong to the secreted Frizzled-related protein (sFRP) family and are rich in cysteine residues (3). They serve an important role as intermediates in growth, development and hematopoietic signaling pathways (4). Wnt inhibitory factor 1 (WIF1) was initially identified in human retinas, and has a negative regulatory role in the $\mathrm{Wnt} / \beta$-catenin signaling pathway (5). WIF1 is an evolutionarily conserved protein encoded by a gene located on chromosome $12 \mathrm{q} 14$, including an N-terminal signal sequence, a WIF1 domain and five consecutive structures similar to domains within epidermal growth factor (5). Abnormal activity of WIF1 has been observed in multiple types of human tumor, including lung cancer (6), prostate cancer (7), breast cancer (8), bladder cancer (9) and nasopharyngeal carcinoma (10). WIF1 exhibits marked perinuclear expression in wild-type lung, prostate, breast and bladder epithelial cells (6-9). However, the expression of WIF1 was decreased significantly in $23 \%$ of prostate cancer, $60 \%$ of breast cancer, $75 \%$ of non-small cell lung cancer and $26 \%$ of bladder cancer cases (11). In non-small cell lung cancer, prostate cancer and breast cancer, no association 
was observed between progression stage and decreased expression of WIF1. These observations indicated that, with the exception of bladder cancer, where the expression of WIF1 was decreased in advanced stages, the expression of WIF1 in these tumor tissues was decreased during the early stages (11). WIF1 mRNA and protein expression was decreased in $80 \%$ of esophageal cancer, $74 \%$ of gastric cancer, $82 \%$ of colorectal cancer and $75 \%$ of pancreatic cancer cases (12).

Receptor tyrosine kinase-like orphan receptor 2 (ROR2) is a member of the receptor tyrosine kinase (RTK) family (13). A number of members of the RTK family serve an important role in the morphogenesis and histodifferentiation of mammalian cells (14). It has also been demonstrated that ROR2 is able to participate in signaling as the receptor of protein Wnt5a precursor (Wnt5a) between the Janus kinase-signal transducer and activator of transcription 3, and Wnt/c-Jun N-terminal kinase signaling pathways $(15,16)$. According to previous studies, ROR2 expression is associated with the tumorigenesis, progression, biological behavior and prognosis of various types of malignant tumor, including gastric cancer (17), rectal carcinoma (18), liver cancer (19), breast cancer (20), esophageal squamous cell carcinoma (20) and medulloblastoma (21). Furthermore, studies have demonstrated that the majority of malignant tumor types with elevated ROR2 expression levels exhibited poor differentiation ability, advanced clinical stage, and increased metastasis and invasion, indicating that patients with increased ROR2 expression exhibit a poor prognosis $(22,23)$. As a result, ROR2 may prove to be an important biomarker in the prognosis of patients with malignant tumors (24).

In the present study, the expression levels of WIF1 and ROR2 protein were studied in 106 patients with pancreatic ductal carcinoma, 35 patients with paracancerous tissue, 55 patients with benign lesions and 13 wild-type pancreatic tissues. The clinical and pathological significance were also studied to further examine the potential association between expression levels of WIF1 and ROR2 protein, and the prognosis of patients with pancreatic ductal carcinoma.

\section{Materials and methods}

Tissue specimens. Pancreatic cancer biopsies from 106 patients with pancreatic cancer who had undergone surgery were collected between January 2000 and December 2011 at the Hepatobiliary Surgery Department of the Second Xiangya Hospital of Central South University (Changsha, China) and the Department of General Surgery of the Third Xiangya Hospital of Central South University (Changsha, China). The present study was approved by the Human Ethics Committee of Central South University and patients provided written informed consent. Biopsies were from patients who were all diagnosed with pancreatic ductal carcinoma who did not accept radiotherapy and/or chemotherapy treatment prior to surgery. There were 61 males (57.5\%) and 45 females (42.5\%). The mean age of the patients was $54.50 \pm 11.53$ years, with 22 patients $<45$ years of age $(20.8 \%)$ and 84 patients $>45$ years of age $(79.2 \%)$. The pathological features of the cancer included 38 well-differentiated adenocarcinomas (35.8\%), 35 moderately differentiated adenocarcinomas (33.0\%) and 33 poorly differentiated adenocarcinomas $(31.1 \%)$. The tumor diameter ranged between $<3 \mathrm{~cm}$ (13 patients, $12.2 \%), 3-5 \mathrm{~cm}$
(68 patients, $64.1 \%$ ), and $>5 \mathrm{~cm}$ (25 patients, $23.5 \%$ ). A total of 29 patients $(27.3 \%)$ were diagnosed with regional lymph node metastases outside the pancreas, and 77 patients (72.6\%) were negative for lymph node metastasis following pathological section examination. During surgery, 64 patients $(60.4 \%)$ were observed to be positive and 42 patients $(39.6 \%)$ were observed to be negative for invasion of the surrounding organ. For the clinical tumor, node, metastasis (TNM) staging, 11 patients $(10.4 \%)$ were in stage I, 42 patients $(39.6 \%)$ were in stage II, 37 patients $(34.9 \%$ ) were in stage III and 16 patients $(15.1 \%)$ were in stage IV. Furthermore, when paracancerous epithelial tissue from 35 patients, including 18 males and 17 females, median age 56 years, with pancreatic ductal cancer was collected between January 2000 and December 2011 (distance from the cancer tissue, $\geq 2 \mathrm{~cm}$ ) at the Hepatobiliary Surgery Department of the Second Xiangya Hospital of Central South University and the Department of General Surgery of the Third Xiangya Hospital of Central South University, 12 cases were diagnosed as wild-type, 10 cases were diagnosed as atypical hyperplasia, 8 cases were diagnosed as medium atypical hyperplasia and 5 cases were diagnosed as severe atypical hyperplasia.

Biopsies from surgical resections were collected from 55 patients at the Hepatobiliary Surgery Department of the Second Xiangya Hospital of Central South University between January 2000 and December 2011. There were 29 males (52.7\%) and 26 females (47.3\%). The ages of the patients were $<45$ years (13 patients, $23.6 \%$ ) or $>45$ years (42 patients, $76.4 \%$ ). The mean age of the patients was $51.30 \pm 10.26$ years). The pathological features were chronic pancreatitis (20 cases, 36.4\%), adenoma (20 cases, 36.4\%) and epithelial neoplasia (15 cases, 27.3\%). Chronic pancreatitis cases were categorized as mild (10 cases), moderate (6 cases) and severe (4 cases). Among these patients with chronic pancreatitis, three patients had complications with slight atypical hyperplasia, six patients had complications with moderate atypical hyperplasia and four patients had complications with severe atypical hyperplasia. In addition to these categories, the glandular epithelium demonstrated atypical hyperplasia in three patients, moderate hyperplasia in two patients and severe atypical hyperplasia in one patient. With respect to the adenoma, there were 15 cases of serous adenoma and five cases of mucous adenoma, among which the glandular epithelium demonstrated mild atypical hyperplasia in four patients, moderate atypical hyperplasia in three patients and severe atypical hyperplasia in two patients. For the intraepithelial neoplasia, six cases were of grade I, five cases were of grade II and four cases were of grade III. Wild-type pancreatic tissue of 13 cases was also collected to serve as a control. All aforementioned biopsy samples were fixed in $4 \%$ formaldehyde at room temperature for $24-48 \mathrm{~h}$ following collection and embedded in paraffin followed by sectioning at $4 \mu \mathrm{m}$.

Immunostaining. The rabbit-anti-human WIF-1 (cat. no. AP2723b; dilution, 1:50) and rabbit-anti-human ROR2 (cat. no., AP7672d; dilution, 1:50) polyclonal antibodies were purchased from Abgent (San Diego, California, USA). WIF-1 and ROR2 immunohistochemistry was carried out using the EnVision $^{\mathrm{TM}}$ system [ChemMate ${ }^{\mathrm{TM}}$ EnVison+/horseradish peroxidase (HRP)/3,3'-diaminobenzidine (DAB), rabbit/mouse two step staining method], according to the protocol of the manufacturer (Dako; Agilent Technologies, Inc., Santa Clara, 
Table I. Expression of WIF1 and ROR2 protein in benign and malignant pancreatic lesions.

\begin{tabular}{lrrr}
\hline Tissue type & $\mathrm{n}$ & WIF1-positive, n (\%) & ROR2-positive, n (\%) \\
\hline Pancreatic ductal carcinoma & 106 & $55(51.9)$ & $55(51.9)$ \\
Paracancerous epithelium & 35 & $29(82.8)^{\mathrm{a}}$ & $10(28.6)^{\mathrm{a}}$ \\
Benign lesions & 55 & $48(87.5)^{\mathrm{a}}$ & $11(20.0)^{\mathrm{a}}$ \\
Wild-type tissue & 13 & $13(100.0)^{\mathrm{a}}$ & $0(0.0)^{\mathrm{a}}$ \\
\hline
\end{tabular}

${ }^{a} \mathrm{P}<0.01$ vs. pancreatic ductal carcinoma. ROR2, receptor tyrosine kinase-like orphan receptor 2; WIF1, Wnt inhibitory factor 1 .

CA, USA). The slides were dried overnight at $65^{\circ} \mathrm{C}$, deparaffinized in xylene and dehydrated using a series of graded alcohols. Heat-induced epitope retrieval was conducted with sodium citrate buffer (10 mM sodium citrate, $0.05 \%$ Tween-20, $\mathrm{pH} 6.0$ ) at $96^{\circ} \mathrm{C}$ for $30 \mathrm{~min}$. Endogenous peroxidase activity was inhibited by incubating the sections in $3 \%$ hydrogen peroxide for $15 \mathrm{~min}$ at room temperature. Nonspecific binding sites were blocked with $10 \%$ normal goat serum for $10 \mathrm{~min}$. The slides were incubated with $50 \mu 1$ rabbit anti-human WIF-1 and rabbit-anti-human ROR 2 at $37^{\circ} \mathrm{C}$ for $1 \mathrm{~h}$. The slides were washed in PBS 3 times for $5 \mathrm{~min}$. The sections were incubated with $50 \mu$ l Solution A (ChemMateTMEnVison+/HRP) at $37^{\circ} \mathrm{C}$ for $30 \mathrm{~min}$ and washed in PBS 3 times for $5 \mathrm{~min}$. DAB (Dako Real DAB+Chromogen, K5007) was applied for 2 min and removed by rinsing with distilled water. The slides were counterstained with hematoxylin. The sections were dehydrated, soaked in xylene, and mounted with neutral resin.

Cells with brown punctate perinuclear staining following immunostaining with anti-WIF1 antibody were considered positive, and cells with cytoplasmic staining following immunostaining with anti-ROR2 antibody were considered ROR2-positive. A total of 400 cancer cells in 10 high-power fields (magnification, x400 using an Olympus BX51 microscope) were scored randomly to determine the proportion of positive cells. Cases with $\geq 25 \%$ positive cells were considered positive and cases with $<25 \%$ positive cells were considered negative. Positive sections purchased from Beijing Zhongshan Jinqiao Biotechnology Co., Ltd. (Beijing, China) were used as the positive controls and 5\% $0.01 \mathrm{~mol} / \mathrm{l} \mathrm{PBS}$ ( $\mathrm{pH}$ 7.4) was used instead of WIF1 and ROR2 antibodies as the negative control.

Statistical analysis. All experimental data were analyzed using SPSS software (version 13.0; SPSS, Inc., Chicago, IL, USA). A $\chi^{2}$ test or Fisher's exact test was used to analyze the association between WIF1 and ROR2 protein expression, and the histological and clinical factors. The Kaplan-Meier estimator was used for univariate survival analysis and the log-rank test. The Cox proportional hazards model (LR method; $\mathrm{P}<0.05$ for inclusion) was used for multivariate survival analysis and to determine the odds ratios (OR) $95 \%$ confidence interval $(95 \% \mathrm{CI}) . \mathrm{P}<0.05$ indicated statistical significance.

\section{Results}

Expression of WIF1 and ROR 2 protein in wild-type pancreatic tissue samples, and in the benign and malignant pancreatic lesions. Among the 106 patients with pancreatic ductal carcinoma, 55 patients $(51.9 \%)$ were identified as exhibiting positive WIF1 and ROR2 protein expression. Among the 35 paracancerous tissue samples, the number of cases with positive WIF1 and ROR2 protein expression were 29 (82.8\%) and 10 (28.6\%), respectively. Among the 55 patients with pancreatic benign lesions, the number of cases with positive WIF1 and ROR2 protein expression was $48(87.5 \%)$ and 11 (20.0\%), respectively. Among the 13 patients with wild-type pancreatic tissue, global positive and negative expression of WIF1 and ROR2 protein, respectively, was demonstrated. The positive expression rate of WIF1 protein in the pancreatic ductal carcinoma was significantly decreased compared with the paracancerous tissue $\left(\chi^{2}=10.479, \mathrm{P}=0.002\right)$, benign lesions $\left(\chi^{2}=19.674, \mathrm{P}<0.0001\right)$ and wild-type pancreatic tissue $\left(\chi^{2}=10.946, \mathrm{P}=0.001\right)$; however, the positive expression rate of ROR 2 protein in the pancreatic ductal carcinoma was significantly increased compared with that the paracancerous tissue $\left(\chi^{2}=27.336, \mathrm{P}<0.0001\right.$, benign lesions $\left(\chi^{2}=15.221, \mathrm{P}<0.0001\right)$ and the wild-type pancreatic tissue $\left(\chi^{2}=12.542, \mathrm{P}<0.0001\right)$. In addition, ductal epithelium of paracancerous tissue and benign tissue with negative WIF1 protein expression and positive ROR 2 protein expression all presented mild to severe atypical hyperplasia or intraepithelial neoplasia, in grades II and III (Table I; Figs. 1 and 2). Among the benign lesions, positive WIF1 protein expression rates in chronic pancreatitis, adenoma and intraepithelial neoplasia were, 90.0\% (18/20), 90.0\% (18/20) and 80.0\% (12/15), respectively, whereas positive ROR 2 protein expression rates in chronic pancreatitis, adenoma and intraepithelial neoplasia were, $15.0 \%$ (3/20), $20.0 \%(4 / 20)$ and $26.7 \%$ (4/15), respectively. No significant differences between the positive WIF1 and ROR2 protein expression rate among the three types of benign lesions were identified $(\mathrm{P}>0.05)$.

Association between WIF1 and ROR2 protein expression, and the clinicopathological features of pancreatic ductal carcinoma. Positive expression rates of WIF1 protein were increased in cases that were well differentiated, with a maximum tumor diameter of $<3 \mathrm{~cm}$, and that had no lymph node metastasis or surrounding organ invasion, and that were of TNM stage I/II compared with in cases that were poorly differentiated, with a maximum tumor diameter of $>5 \mathrm{~cm}$, that had lymph node metastases with surrounding organ invasion and that were of TNM stage III/IV $(\mathrm{P}<0.05)$. By contrast, positive ROR2 protein expression rates were significantly decreased in cases that were well differentiated, with a maximum tumor diameter of $<3 \mathrm{~cm}$, that had no lymph node metastasis or surrounding organ invasion 

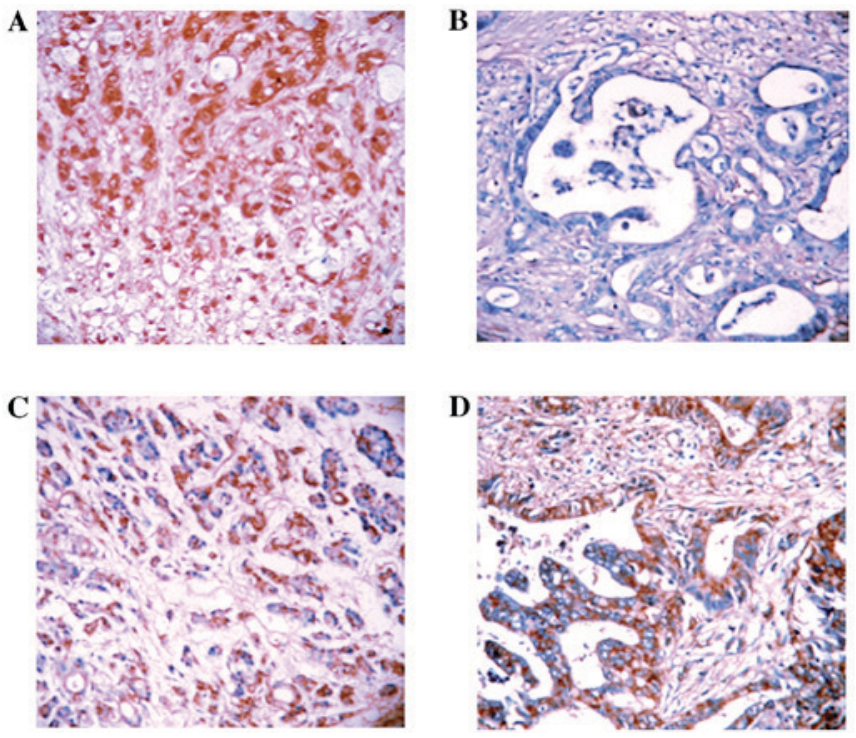

Figure 1. Expression of WIF1 protein in benign and malignant pancreatic lesions. Representative images of immunohistochemical analysis (magnification, x200). (A) Positive WIF1 protein expression in moderately differentiated adenocarcinoma. (B) Negative WIF1 protein expression in poorly differentiated adenocarcinoma. (C) Positive WIF1 protein expression in grade II intraepithelial neoplasia. (D) Positive WIF1 protein expression in paracancerous tissue. WIF1, Wnt inhibitory factor 1 .

and that were of TNM stage I/II compared with in cases that were poorly differentiated, with a maximum tumor diameter $>5 \mathrm{~cm}$, that had lymph node metastases and surrounding organ invasion and that were of TNM stage III/IV $(\mathrm{P}<0.05)$. No statistically significant association between the age or gender of the patients and the positive expression rates of WIF1 and ROR2 protein was identified $\left(\chi^{2}=8.601, \mathrm{P}>0.05\right.$; Table II $)$.

Association between WIF1 and ROR2 protein expression in pancreatic ductal carcinoma. Among the 55 patients with positive WIF1 protein expression, there were 21 cases that were also positive for ROR2 protein expression. Of the 51 patients with negative WIF1 protein expression, there were 17 cases that were also negative for ROR2 protein expression. Therefore, a statistically significant inverse association between WIF1 and ROR2 protein expression was identified $(\mathrm{P}=0.004)$.

Association among mean survival rate, clinicopathological indicators, and expression of WIF1 and ROR2 protein in patients with pancreatic ductal carcinoma. Samples were collected from 106 patients with pancreatic ductal carcinoma via paper correspondence or through call returning visits. The follow-ups continued for 2 years. Patients who survived for 2 years were included in the statistical analysis as censored cases. Among these cases, 29 patients had a post-operative survival period of $\geq 1$ year, whereas 77 patients had a post-operative survival period of $<1$ year (mean, $9.44 \pm 0.69$ months). Using Kaplan-Meier estimator survival analysis, a statistically significant correlation between the differentiation level, maximum tumor diameter, TNM stage, lymph node metastasis and surrounding organ invasion, and the mean survival time of patients with pancreatic ductal carcinoma was identified $(\mathrm{P}<0.05)$. The mean survival time of WIF1-positive patients was significantly increased compared
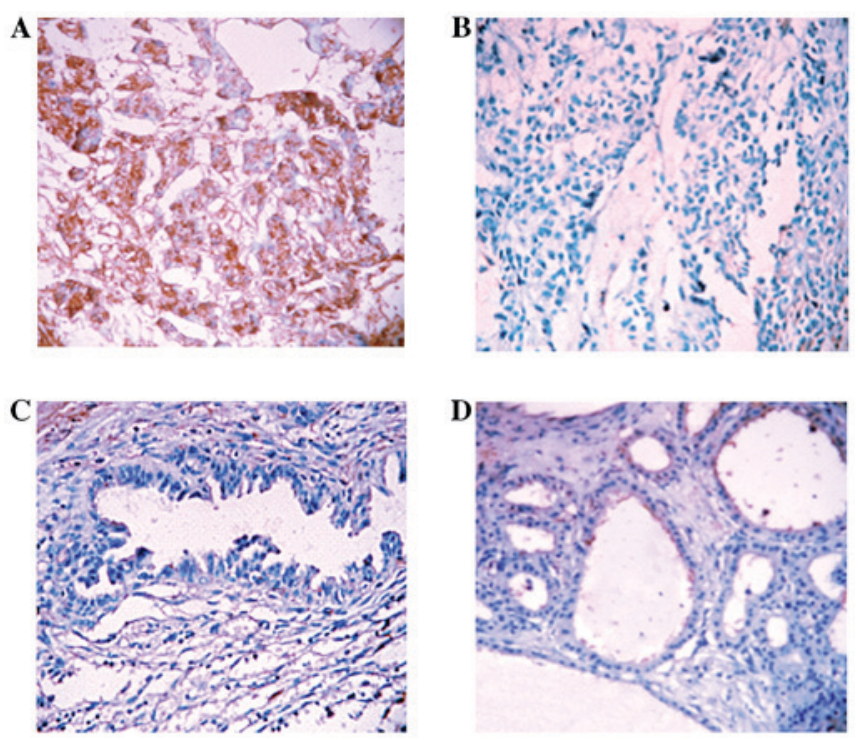

Figure 2. Expression of ROR2 protein in benign and malignant pancreatic lesions. Representative images of immunohistochemical analysis (magnification, x200). (A) Positive ROR2 protein expression in moderately differentiated adenocarcinoma. (B) Negative ROR2 protein expression in well differentiated adenocarcinoma. (C) Positive ROR2 protein expression in chronic pancreatitis tissues. (D) Negative ROR2 protein expression in adenoma tissues. ROR2, receptor tyrosine kinase-like orphan receptor 2.

with cases that were WIF1-negative $(\mathrm{P}<0.0001$; Table III and Fig. 3). The mean survival time of ROR2-positive cases was significantly decreased compared with that of ROR2-negative cases $(\mathrm{P}<0.0001$; Table III and Fig. 3). Cox's proportional hazards model demonstrated that, although there was a negative correlation between poor differentiation, maximum tumor diameter of $<3 \mathrm{~cm}$, TNM stage III/IV, lymph node metastasis, surrounding organ invasion and the post-operative survival rate, there was a positive correlation between these factors and the death rate. These results indicated that these factors were risk factors and independent prognostic factors. Positive WIF1 protein expression had a positive correlation with the post-operative survival rate and a negative correlation with the post-operative death rate, making it a protective factor; however, positive ROR2 protein expression was identified to have a negative correlation with the post-operative survival rate and a positive correlation with the death rate, making it a risk factor (Table IV). Therefore, WIF1 and ROR2 are independent prognostic factors.

\section{Discussion}

The Wnt signaling pathway is characterized into the classical and the non-classical signaling pathways. The Wnt receptor protein complex includes Frizzled, low-density lipoprotein (LRP) 5 and LRP6 (25-27). Due to their function and the means by which they bind Wnts and their receptors, WIF1, sFRP and Cerberus belong to the Wnt antagonist family. Wnt antagonists prevent Wnt from binding with its receptor protein complex by directly binding to the Wnt protein, $\beta$-catenin is targeted to a multimeric protein complex called destruction complex for its phosphorylation. This is achieved by CK1-mediated phosphorylation at Ser45, followed by Ser33, Ser37, and Thr41 phosphorylation by glycogen synthase kinase 
Table II. Association between WIF1 and ROR2 protein expression, and the clinicopathological characteristics of patients with pancreatic ductal carcinoma.

\begin{tabular}{|c|c|c|c|c|c|c|c|}
\hline \multirow{2}{*}{$\begin{array}{l}\text { Clinicopathological } \\
\text { characteristic }\end{array}$} & \multirow[b]{2}{*}{$\mathrm{n}$} & \multicolumn{3}{|c|}{ WIF1 } & \multicolumn{3}{|c|}{ ROR2 } \\
\hline & & Positive, n (\%) & $\chi^{2}$ & $\mathrm{P}$-value & Positive, $\mathrm{n}(\%)$ & $\chi^{2}$ & P-value \\
\hline Gender & & & 0.854 & 0.356 & & 0.066 & 0.798 \\
\hline Male & 61 & $34(55.7)$ & & & $31(50.8)$ & & \\
\hline Female & 45 & $21(46.7)$ & & & $24(53.3)$ & & \\
\hline Age, years & & & 0.460 & 0.498 & & 2.953 & 0.086 \\
\hline$\leq 45$ & 22 & $10(45.5)$ & & & $15(68.2)$ & & \\
\hline$>45$ & 84 & $45(53.6)$ & & & $40(47.6)$ & & \\
\hline Differentiation status & & & 6.130 & 0.047 & & 6.114 & 0.047 \\
\hline Well & 38 & $25(65.8)$ & & & $17(44.7)$ & & \\
\hline Moderate & 35 & $18(51.4)$ & & & $15(42.9)$ & & \\
\hline Poor & 33 & $12(36.4)$ & & & $23(69.7)$ & & \\
\hline Tumor size, $\mathrm{cm}$ & & & 4.268 & 0.118 & & 5.019 & 0.081 \\
\hline$\leq 3$ & 13 & $9(69.2)$ & & & $4(30.8)$ & & \\
\hline $3-5$ & 68 & 37 (54.4) & & & $34(50.0)$ & & \\
\hline$>5$ & 25 & $9(36.0)$ & & & $17(68.0)$ & & \\
\hline Lymph node metastasis & & & 12.314 & $<0.0001$ & & 18.836 & $<0.0001$ \\
\hline Absent & 77 & $48(62.3)$ & & & $30(39.0)$ & & \\
\hline Present & 29 & $7(24.1)$ & & & $25(86.2)$ & & \\
\hline TNM stage & & & 24.532 & $<0.0001$ & & 22.570 & $<0.0001$ \\
\hline I & 11 & $10(90.9)$ & & & $2(18.2)$ & & \\
\hline II & 42 & $29(69.0)$ & & & $14(33.3)$ & & \\
\hline III & 37 & $14(37.8)$ & & & 25 (67.6) & & \\
\hline IV & 16 & $2(12.5)$ & & & $14(87.5)$ & & \\
\hline Invasion & & & 23.540 & $<0.0001$ & & 25.850 & $<0.0001$ \\
\hline Absent & 42 & $34(81.0)$ & & & $9(21.4)$ & & \\
\hline Present & 64 & $21(32.8)$ & & & $46(71.9)$ & & \\
\hline
\end{tabular}

ROR2, receptor tyrosine kinase-like orphan receptor 2; WIF1, Wnt inhibitory factor 1 ; TNM, tumor, node, metastasis. When there were $>2$ classifications for the characteristic the $\chi^{2}$ value of $\chi^{2}$-test means there was a difference between multiple classifications in the characteristic.

(GSK) $3 \beta$ (28), which leads to decreased cytoplasmic accumulation of $\beta$-catenin. This further inhibits the classical signaling pathway and the non-classical signaling pathway (29). Transfection of the WIF1 gene into TE-1 esophageal cancer cells or SW48 colon cancer cells inhibited clone formation, cell proliferation and growth in vitro potentially due to loss of WIF1 protein expression. TOPflash analysis demonstrated that, among these cancer cells, WIF1 inhibited the classical pathway (12). A study of the role of WIF1 in lung cancer by Reguart et al (30) demonstrated that the complete WIF1 promoter serves a critical role in the activity of WIF1 and demonstrated that, in cancer cells, the activity of $\beta$-catenin was associated with the activity of WIF1 promoter. These results indicated that the WIF1 promoter may be regulated and controlled by the Wnt/ $\beta$-catenin signaling pathway and serves a negative feedback role. The results of the previous study also demonstrated that, in lung cancer, the methylation of $\mathrm{CpG}$ islands surrounding the WIF1 promoter serves an important role in regulating the activity of the Wnt signaling pathway. In mammals, the methylation of $\mathrm{CpG}$ regulates the expression of genes (31). In cancer, the non-methylated $\mathrm{CpG}$ island sequence of a tumor suppressor gene decreases, whereas the $\mathrm{CpG}$ site in the $\mathrm{CpG}$ island presents an increased level of methylation, enhancing the degree of spiralization of the chromosome and the deactivation of the expression of the tumor suppressor gene (32). Taniguchi et al (12) analyzed the expression of WIF1 in esophageal, gastric, colorectal and pancreatic cancer. The results of the methylation-specific polymerase chain reaction demonstrated that hypermethylation of $\mathrm{CpG}$ islands in the region surrounding the WIF1 promoter was associated with the decreased expression of WIF1 (12). The activity of WIF1 was recovered using 5-aza-2'-deoxycytidine for demethylation, suggesting that cytosine methylation and histone deacetylation serve a role in silencing WIF1 expression (12). As WIF1 inhibits the Wnt signaling pathway, reversing the silencing of WIF1 expression through the use of a demethylating agent may serve a positive role in the treatment or prevention of cancer. Decreased or silenced expression of WIF1 in rectal 
Table III. Association among WIF1 and ROR2 protein expression, clinicopathological characteristics and mean survival of patients with pancreatic ductal carcinoma.

\begin{tabular}{|c|c|c|c|c|}
\hline $\begin{array}{l}\text { Clinicopathological } \\
\text { characteristic }\end{array}$ & $\mathrm{n}$ & $\begin{array}{l}\text { Mean survival, } \\
\text { months (range) }\end{array}$ & $\chi^{2}$ & P-value \\
\hline Age, years & & & 2.144 & 0.143 \\
\hline$\leq 45$ & 22 & $8.18(3-19)$ & & \\
\hline$>45$ & 84 & $9.73(2-24)$ & & \\
\hline Gender & & & 1.656 & 0.198 \\
\hline Male & 61 & $9.98(2-24)$ & & \\
\hline Female & 45 & $8.61(2-21)$ & & \\
\hline Differentiation status & & & 17.786 & $<0.0001$ \\
\hline Well & 38 & $11.27(3-24)$ & & \\
\hline Moderate & 35 & $9.74(3-21)$ & & \\
\hline Poor & 33 & $6.86(2-14)$ & & \\
\hline Tumor size, $\mathrm{cm}$ & & & 7.504 & 0.023 \\
\hline$\leq 3$ & 13 & $13.46(5-21)$ & & \\
\hline $3-5$ & 68 & $9.34(2-22)$ & & \\
\hline$>5$ & 25 & $7.40(3-24)$ & & \\
\hline Lymph node metastasis & & & 27.120 & $<0.0001$ \\
\hline Absent & 77 & $10.64(2-24)$ & & \\
\hline Present & 29 & $6.35(2-12)$ & & \\
\hline Invasion & & & 46.949 & $<0.0001$ \\
\hline No & 42 & $13.33(5-24)$ & & \\
\hline Yes & 64 & $6.83(2-17)$ & & \\
\hline TNM stage & & & 80.807 & $<0.0001$ \\
\hline I & 11 & $16.46(11-24)$ & & \\
\hline II & 42 & $11.37(3-22)$ & & \\
\hline III & 37 & $7.14(2-17)$ & & \\
\hline IV & 16 & $4.56(2-8)$ & & \\
\hline WIF1 & & & 48.700 & $<0.0001$ \\
\hline- & 51 & $6.33(2-14)$ & & \\
\hline+ & 55 & $12.30(5-24)$ & & \\
\hline ROR2 & & & 38.127 & $<0.0001$ \\
\hline- & 51 & $12.30(5-24)$ & & \\
\hline+ & 55 & $6.70(2-18)$ & & \\
\hline
\end{tabular}

ROR2, receptor tyrosine kinase-like orphan receptor 2; WIF1, Wnt inhibitory factor 1 ; TNM, tumor, node, metastasis. $\chi^{2}$ values obtained by the $\log$-rank $\chi^{2}$-test in survival analysis.

carcinoma, chronic leukemia and pleural mesothelioma was caused by hypermethylation of $\mathrm{CpG}$ islands within the WIF1 promoter (9,33-35). Immunohistochemical analysis indicated that there was a strong immunostaining signal for WIF1 around the nucleus of wild-type epithelial cells of prostate, breast, lung and bladder tissue. However, in $23 \%$ of prostate cancer, $60 \%$ of breast cancer, $75 \%$ of non-small cell lung cancer and $26 \%$ of bladder cancer tissues, the expression of WIF1 decreased markedly (11). There was no significant association between decreased WIF1 expression and tumor development in prostate cancer, breast cancer and non-small cell lung cancer tissues, indicating that WIF1 expression decreased in the early stages of these tumors, whereas in bladder cancer, WIF1 decreased in the later stages (11). The expression of WIF1 mRNA and protein decreased in $80 \%$ of esophageal carcinoma, $74 \%$ of gastric cancer, $82 \%$ of rectal carcinoma and $75 \%$ of pancreatic cancer cases (12).

ROR family receptors belong to the orphan receptor group of RTKs and are evolutionarily conserved. In mammals, the ROR family includes two types of protein, ROR1 and ROR2, which have a similar structure. ROR2 is important in the growth and development of the nervous system and the limbs. Previous studies have demonstrated that ROR is able to participate in the regulation of the classical and non-classical Wnt signaling pathways by binding to Wnt5a, casein kinase I and other factors (36). However, the association between ROR2 and tumor cell migration remains unclear (37). ROR2 protein has three functional domains, including the cytoplasmic 
Table IV. Cox's proportional hazards model of overall survival in pancreatic ductal carcinoma patients.

$95 \%$ confidence interval

\begin{tabular}{lcrrrrrrr}
\cline { 6 - 8 } Characteristic & Classification & $\mathrm{B}$ & $\mathrm{SE}$ & Wald & P-value & RR & Lower & Upper \\
\hline Differentiation & Well/moderate/poor & 1.034 & 0.395 & 6.852 & 0.009 & 2.812 & 1.297 & 6.099 \\
Tumor size, cm & $<3 / 3-5 />5$ & 1.786 & 0.739 & 5.841 & 0.016 & 5.966 & 1.402 & 25.392 \\
Lymph node metastasis & Absent/present & 2.100 & 0.787 & 7.120 & 0.008 & 8.166 & 1.746 & 38.188 \\
Invasion & No/yes & 2.557 & 0.809 & 9.990 & 0.002 & 12.897 & 2.642 & 62.969 \\
TNM stage & I/II/III/IV & 1.552 & 0.501 & 9.596 & 0.002 & 4.721 & 1.768 & 12.603 \\
WIF1 & $-/+$ & -2.774 & 0.858 & 10.453 & 0.001 & 0.062 & 0.012 & 0.335 \\
ROR2 & $-/+$ & 1.995 & 0.704 & 8.030 & 0.005 & 7.352 & 1.850 & 29.220
\end{tabular}

$\mathrm{B}$, regression coefficient; SE, standard error; RR, relative risk; WIF1, Wnt inhibitory factor 1; TNM, tumor, node, metastasis.

A

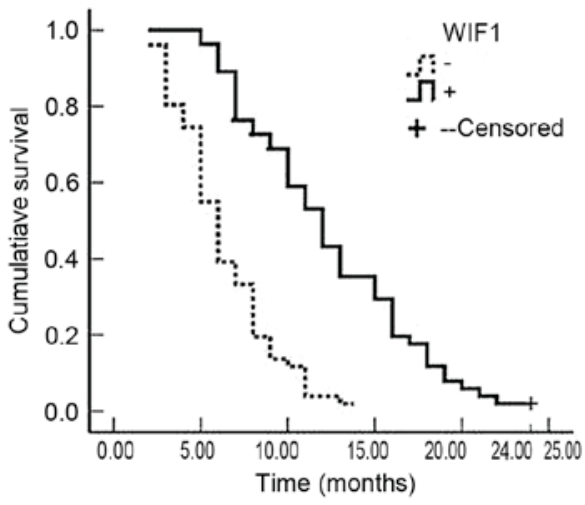

B

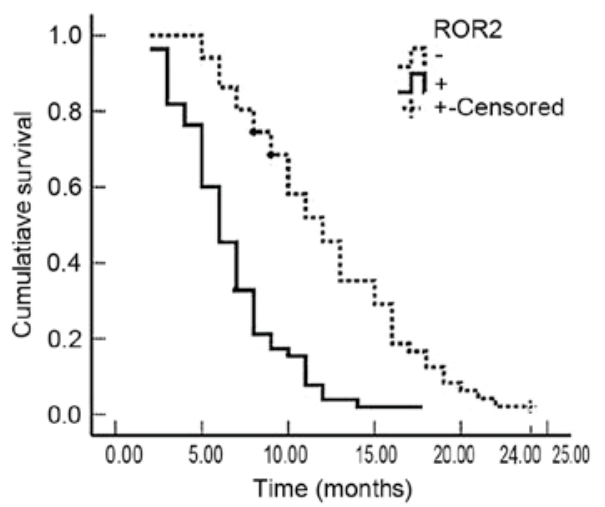

Figure 3. Association between the mean survival rate, and WIF1 and ROR2 protein expression in patients with pancreatic ductal carcinoma. (A) Kaplan-Meier survival curves for patients with positive or negative WIF1 protein expression in pancreatic ductal carcinoma, WIF1 negative, 6.33 vs. positive, 12.3 months, $\mathrm{P}<0.0001$. (B) Kaplan-Meier survival curves for patients with positive or negative ROR2 protein expression in pancreatic ductal carcinoma, ROR2 negative, 12.3 vs. positive, 6.7 months, $\mathrm{P}<0.0001$. Censored data points are from patients who survived for 24 months. WIF1, Wnt inhibitory factor 1 ; ROR 2 , receptor tyrosine kinase-like orphan receptor 2.

domain, the transmembrane domain and the extracellular domain (38). ROR2 was identified to have a Wnt receptor domain-like structure (38). Following Wnt5a binding, the signaling pathway mediated by ROR 2 is activated. The Wnt5a protein may, through this signaling pathway, serve an antagonistic role in the classical Wnt signaling pathway (39-41). However, when Frizzled4 and LRP receptors were expressed on the cell surface, the association between Wnt5a and ROR2 decreased or was eradicated. The role of ROR2 and Wnt5a in cancer is complex, depending on the tumor type and molecular context. ROR2 and Wnt5a prompted the investigation of the possible underlying molecular mechanisms for the diverse roles of Wnt5a in different types of cancer $(39,42-44)$. To the best of our knowledge, there have been few studies on the role of ROR2 in the incidence and development of human cancer. It has been observed that the expression of ROR2 protein is associated with the incidence, development, biological behavior and prognosis of multiple types of malignant tumor, including gastric cancer (14), rectal carcinoma (15), liver cancer (16), breast cancer (17), esophageal squamous cell carcinoma (17) and medulloblastoma (18). Previous studies have identified that malignant tumors with increased ROR2 protein expression levels are frequently poorly differentiated in later clinical stages and exhibit metastasis and invasion, suggesting that ROR2 is an important biomarker in the prognosis of patients with these malignant tumors. Patients with increased ROR2 protein expression may have poor prognoses (42-46).

In the present study, the positive WIF1 protein expression rate in pancreatic ductal carcinoma was significantly decreased compared with that in the paracancerous tissue and benign lesions. However, the opposite phenomenon was observed for the positive ROR2 protein expression rate. In the wild-type pancreatic tissue, WIF1 protein was expressed positively, whereas ROR 2 protein was expressed negatively. Furthermore, the paracancerous epithelium and the ductal epithelium of benign lesions with positive ROR2 and/or negative WIF1 expression displayed, and the ductal epithelium of benign lesions demonstrated mild to severe atypical hyperplasia or intraepithelial neoplasia grade II and III. The positive WIF1 protein expression rate in cases that were well differentiated, with no lymph node metastasis or surrounding organ invasion and at TNM stage I/II was significantly 
increased, compared with that in cases that were poorly differentiated with lymph node metastases, surrounding organ invasion and at TNM stage III/IV. The positive ROR protein expression rate in cases that were well differentiated, with no lymph node metastasis or surrounding organ invasion and at TNM stage I/II was significantly decreased compared with that in cases that were poorly differentiated with lymph node metastases, surrounding organ invasion and at TNM stage I/III/IV. In pancreatic ductal carcinoma, there was a negative association between WIF1 and ROR2 protein expression. Using Kaplan-Meier estimator survival analysis, a statistically significant association between the mean survival time, and the differentiation level, maximum tumor diameter, TNM stage, lymph node metastasis and surrounding organ invasion was identified. The survival time of WIF1-positive cases was significantly increased compared with that of WIF1-negative cases, whereas the survival time of ROR2-positive cases was significantly decreased compared with that of ROR2-negative cases. Cox's proportional hazards model indicated that there was a negative association between the post-operative survival rate, and poor differentiation, a maximum tumor diameter of $\geq 3 \mathrm{~cm}$, TNM stage III/IV, lymph node metastases and surrounding organ invasion; however, there was a positive association between the death rate and these factors. These results indicated that these factors are risk factors and independent prognostic factors. There was a negative association between the post-operative survival rate and negative WIF1 protein expression and positive ROR2 protein expression; however, there was a positive association between the survival rate, and negative WIF1 protein expression and positive ROR2 protein expression. These results indicate that WIF1 and ROR2 are risk factors and independent prognostic factors, and that the protein expression levels of WIF1 and ROR2 reflect the development, biological behavior and prognoses of pancreatic ductal carcinoma. WIF1 and ROR2 may interact with each other in the development of pancreatic ductal carcinoma. Further studies are required to elucidate the underlying molecular mechanisms.

\section{Acknowledgements}

The present study was funded by a general Changsha Science and Technology Plan Project (grant no. K1508038-31).

\section{References}

1. Hidalgo M: Pancreatic cancer. N Engl J Med 362: 1605-1617, 2010.

2. Thomson BN, Banting SW and Gibbs P: Pancreatic cancer-current management. Aust Fam Physician 35: 212-217, 2006.

3. Banziger C, Soldini D, Schütt C, Zipperlen P, Hausmann G and Basler K: Wntless, a conserved membrane protein dedicated to the secretion of Wnt proteins from signaling cells. Cell 125: 509-522, 2006.

4. Miller JR: The Wnts. Genome Biol 3: REVIEWS3001, 2001.

5. Hsieh JC, Kodjabachian L, Rebbert ML, Rattner A, Smallwood PM, Samos CH, Nusse R, Dawid IB and Nathans J: A new secreted protein that binds to Wnt proteins and inhibits their activities. Nature 398: 431-436, 1999.

6. Mazieres J, He B, You L, Xu Z and Jablons DM: Wnt signaling in lung cancer. Cancer Lett 222: 1-10, 2005.

7. Ohigashi T, Mizuno R, Nakashima J, Marumo K and Murai M: Inhibition of Wnt signaling downregulates Akt activity and induces chemosensitivity in PTEN-mutated prostate cancer cells. Prostate 62: 61-68, 2005.
8. Trifa F, Karray-Chouayekh S, Jmal E, Jmaa ZB Khabir A, Sellami-Boudawara T, Frikha M, Daoud J and Mokdad-Gargouri R: Loss of WIF-1 and Wnt5a expression is related to aggressiveness of sporadic breast cancer in Tunisian patients. Tumour Biol 34: 1625-1633, 2013.

9. Urakami S, Shiina H, Enokida H, Kawakami T, Tokizane T, Ogishima T, Tanaka Y, Li LC, Ribeiro-Filho LA, Terashima M, et al: Epigenetic inactivation of Wnt inhibitory factor-1 plays an important role in bladder cancer through aberrant canonical Wnt/beta-catenin signaling pathway. Clin Cancer Res 12: 383-391, 2006.

10. Fendri A, Khabir A, Hadri-Guiga B, Sellami-Boudawara T, Daoud J, Frikha M, Ghorbel A, Gargouri A and Mokdad-Gargouri R: Epigenetic alteration of the Wnt inhibitory factor-1 promoter is common and occurs in advanced stage of Tunisian nasopharyngeal carcinoma. Cancer Invest 28: 896-903, 2010.

11. Wissmann C, Wild PJ, Kaiser S, Roepcke S, Stoehr R, Woenckhaus M, Kristiansen G, Hsieh JC, Hofstaedter F, Hartmann A, et al: WIF1, a component of the Wnt pathway, is down-regulated in prostate, breast, lung, and bladder cancer. J Pathol 201: 204-212, 2003.

12. Taniguchi H, Yamamoto H, Hirata T, Miyamoto N, Oki M, Nosho K, Adachi Y, Endo T, Imai K and Shinomura Y: Frequent epigenetic inactivation of Wnt inhibitory factor- 1 in human gastrointestinal cancers. Oncogene 24: 7946-7952, 2005.

13. Morioka K, Tanikawa C, Ochi K, Daigo Y, Katagiri T, Kawano H, Kawaguchi H, Myoui A, Yoshikawa H, Naka N, et al: Orphan receptor tyrosine kinase ROR2 as a potential therapeutic target for osteosarcoma. Cancer Sci 100: 1227-1233, 2009.

14. Forrester WC: The Ror receptor tyrosine kinase family. Cell Mol Life Sci 59: 83-96, 2002.

15. Ford CE, Qian Ma SS, Quadir A and Ward RL: The dual role of the novel Wnt receptor tyrosine kinase, ROR2, in human carcinogenesis. Int J Cancer 133: 779-787, 2013.

16. Ren D, Minami Y and Nishita M: Critical role of Wnt5a-Ror2 signaling in motility and invasiveness of carcinoma cells following Snail-mediated epithelial-mesenchymal transition. Genes Cells 16: 304-315, 2011.

17. Kubo T, Kuroda Y, Shimizu H, Kokubu A, Okada N, Hosoda F, Arai Y, Nakamura Y, Taniguchi $\mathrm{H}$, Yanagihara $\mathrm{K}$, et al: Resequencing and copy number analysis of the human tyrosine kinase gene family in poorly differentiated gastric cancer. Carcinogenesis 30: 1857-1864, 2009.

18. Lara E, Calvanese V, Huidobro C, Fernández AF, Moncada-Pazos A, Obaya AJ, Aguilera O, González-Sancho JM, Sánchez L, Astudillo A, et al: Epigenetic repression of ROR2 has a Wnt-mediated, pro-tumourigenic role in colon cancer. Mol Cancer 9: 170, 2010.

19. Liu S, Gong J, Morishita A, Nomura T, Miyoshi H, Tani J, Kato K, Yoneyama H, Deguchi A, Mori H, et al: Use of protein array technology to investigate receptor tyrosine kinases activated in hepatocellular carcinoma. Exp Ther Med 2: 399-403, 2011.

20. Li L, Ying J, Tong X, Zhong L, Su X, Xiang T, Shu X, Rong R, Xiong L, Li H, et al: Epigenetic identification of receptor tyrosine kinase-like orphan receptor 2 as a functional tumor suppressor inhibiting $\beta$-catenin and AKT signaling but frequently methylated in common carcinomas. Cell Mol Life Sci 71: 2179-2192, 2014.

21. Lee SE, Lim SD, Kang SY, Suh SB and Suh YL: Prognostic significance of Ror2 and Wnt5a expression in medulloblastoma. Brain Pathol 23: 445-453, 2013.

22. Lu BJ, Wang YQ, Wei XJ, Rong LQ, Wei D, Yan CM, Wang DJ and Sun JY: Expression of WNT-5a and ROR2 correlates with disease severity in osteosarcoma. Mol Med Rep 5: 1033-1036, 2012.

23. O'Connell MP, Fiori JL, Xu M, Carter AD, Frank BP, Camilli TC, French $\mathrm{AD}$, Dissanayake SK, Indig FE, Bernier M, et al: The orphan tyrosine kinase receptor, ROR2, mediates Wnt5A signaling in metastatic melanoma. Oncogene 29: 34-44, 2010.

24. Geng M, Cao YC, Chen YJ, Jiang H, Bi LQ and Liu XH: Loss of Wnt5a and Ror2 protein in hepatocellular carcinoma associated with poor prognosis. World J Gastroenterol 18: 1328-1338, 2012.

25. Pinson KI, Brennan J, Monkley S, Avery BJ and Skarnes WC: An LDL-receptor-related protein mediates Wnt signalling in mice. Nature 407: 535-538, 2000.

26. Tamai K, Semenov M, Kato Y, Spokony R, Liu C, Katsuyama Y, Hess F, Saint-Jeannet JP and He X: LDL-receptor-related proteins in Wnt signal transduction. Nature 407: 530-535, 2000. 
27. Wehrli M, Dougan ST, Caldwell K, O'Keefe L, Schwartz S, Vaizel-Ohayon D, Schejter E, Tomlinson A and DiNardo S: Arrow encodes an LDL receptor-related protein essential for Wingless signalling. Nature 407: 527-530, 2000.

28. Liu C, Li Y, Semenov M, Han C, Baeg GH, Tan Y, Zhang Z, Lin $\mathrm{X}$ and He X: Control of beta-catenin phosphorylation/degradation by a dual-kinase mechanism. Cell 108: 837-847, 2002.

29. Rao TP and Kühl M: An updated overview on Wnt signaling pathways: A prelude for more. Circ Res 106: 1798-1806, 2010.

30. Reguart N, He B, Xu Z, You L, Lee AY, Mazieres J, Mikami I, Batra S, Rosell R, McCormick F and Jablons DM: Cloning and characterization of the promoter of human Wnt inhibitory factor-1. Biochem Biophys Res Commun 323: 229-234, 2004.

31. Hendrich B and Bird A: Identification and characterization of a family of mammalian methyl-CpG binding proteins. Mol Cell Biol 18: 6538-6547, 1998.

32. Ullah F, Khan T, Ali N, Malik FA, Kayani MA, Shah ST and Saeed M: Promoter methylation status modulate the expression of tumor suppressor (RbL2/p130) gene in breast cancer. PLoS One 10: e0134687, 2015.

33. Shimomura H, Hayashi S, Yokota K, Oguma K and Hirai Y: Alteration in the composition of cholesteryl glucosides and other lipids in Helicobacter pylori undergoing morphological change from spiral to coccoid form. FEMS Microbiol Lett 237: 407-413, 2004.

34. He B, Reguart N, You L, Mazieres J, Xu Z, Lee AY, Mikami I, McCormick F and Jablons DM: Blockade of Wnt-1 signaling induces apoptosis in human colorectal cancer cells containing downstream mutations. Oncogene 24: 3054-3058, 2005.

35. Chim CS, Fung TK, Wong KF, Lau JS and Liang R: Infrequent Wnt inhibitory factor-1 (Wif-1) methylation in chronic lymphocytic leukemia. Leuk Res 30: 1135-1139, 2006.

36. Batra S, Shi Y, Kuchenbecker KM, He B, Reguart N, Mikami I, You L, Xu Z, Lin YC, Clément G and Jablons DM: Wnt inhibitory factor-1, a Wnt antagonist, is silenced by promoter hypermethylation in malignant pleural mesothelioma. Biochem Biophys Res Commun 342: 1228-1232, 2006.
37. Oishi I, Takeuchi S, Hashimoto R, Nagabukuro A, Ueda T, Liu ZJ, Hatta T, Akira S, Matsuda Y, Yamamura H, et al: Spatio-temporally regulated expression of receptor tyrosine kinases, mRor1, mRor2, during mouse development: Implications in development and function of the nervous system. Genes Cells 4: 41-56, 1999.

38. Sehlessinger J: Cell signaling by receptor tyrosine kinase. Cell 103: 211-225, 2000

39. DeChiara TM, Kimble RB, Poueymirou WT, Rojas J, Masiakowski P, Valenzuela DM and Yancopoulos GD: ROR2, encoding a receptor-like tyrosine kinase, is required for cartilage and growth plate development. Nat Genet 24: 271-274, 2000.

40. Oishi I, Suzuki H, Onishi N, Takada R, Kani S, Ohkawara B, Koshida I, Suzuki K, Yamada G, Schwabe GC, et al: The receptor tyrosine kinase ROr2 is involved in non-canonical Wnt5a/JNK signaling pathway. Genes Cells 8: 645-654, 2003.

41. Cheng R, Sun B, Liu Z, Zhao X, Qi L, Li Y and Gu Q: Wnt5a suppresses colon cancer by inhibiting cell proliferation and epithelial-mesenchymal transition. J Cell Physiol 229: 1908-1917, 2014.

42. Jiang W, Crossman DK, Mitchell EH, Sohn P, Crowley MR and Serra R: WNT5A inhibits metastasis and alters splicing of Cd44 in breast cancer cells. PLoS One 8: e58329, 2013.

43. Lejeune S, Huguet EL, Hamby A, Poulsom R and Harris AL: Wnt5a cloning, expression, and up-regulation in human primary breast cancers. Clin Cancer Res 1: 215-222, 1995.

44. Kanzawa M, Semba S, Hara S, Itoh T and Yokozaki H: WNT5A is a key regulator of the epithelial-mesenchymal transition and cancer stem cell properties in human gastric carcinoma cells. Pathobiology 80: 235-244, 2013.

45. Mikels AJ and Nusse R: Purified Wnt5a protein activates or inhibits beta-catenin-TCF signaling depending on receptor context. PLoS Biol 4: e115, 2006.

46. Lu C, Wang X, Zhu H, Feng J, Ni S and Huang J: Over-expression of ROR2 and Wnt5a cooperatively correlates with unfavorable prognosis in patients with non-small cell lung cancer. Oncotarget 6: 24912-24921, 2015. 